\title{
Editorial: Stress Field Control of Eruption Dynamics
}

\author{
Roberto Sulpizio ${ }^{1 *}$, Antonio Costa ${ }^{2}$ and Geoffrey Wadge ${ }^{3}$ \\ ${ }^{1}$ Dipartimento di Scienze della Terra e Geoambientali, Università degli Studi di Bari Aldo Moro, Bari, Italy, ${ }^{2}$ Istituto Nazionale \\ di Geofisica e Vulcanologia, Bologna, Italy, ${ }^{3}$ Centre for Observation and Modelling of Earthquakes, Volcanoes and Tectonics \\ (COMET), Department of Meteorology, University of Reading, Reading, United Kingdom
}

Keywords: volcanology, stress-field, eruption trigger, eruption dynamics, tectonic stress

\section{Editorial on the Research Topic}

\section{Stress Field Control of Eruption Dynamics}

The state of stress in the Earth's crust is a fundamental geophysical variable. That stress is transmitted across the boundaries between magma bodies and their host rocks, forming an undoubted potential causal link. But for almost all volcanoes we have no direct observational knowledge of the state of stress within and below them.

We know, in general, that the 3D field of stress acting on a volcanic system can dramatically affect eruption dynamics controlling processes of magma storage and magma ascent to the surface. Stresses act at different scales, and both local to regional stress can significantly affect rock-magma mechanics in a very complex way because of nonlinear interactions between the different parts of the volcanic system and heterogeneity of the Earth's crust. A change in stress within the magmatic system can play a fundamental role in triggering or modifying the style of volcanic eruptions, and even reawakening a dormant system. There are many forcing agents of changes in stress, including earthquakes, erosion and landslides, deglaciation, and tidal effects. The local stress can change also as response of magma influx from deeper reservoirs and an increase of the magma/gas pressure. Such changes can occur on different time scales dictating variations in the behavior of a volcanic system. Change in local tectonic stress has been invoked as a trigger of large ignimbrite eruptions or for controlling the eruptive style of explosive eruptions. Sometimes volcano systems that are closely located may become active in chorus after strong earthquakes. Some studies suggest that volcanic eruptions are triggered if compressive stress acts at the magma system and "squeezes" out magma (Rikitake and Sato, 1989). Other studies suggest that horizontally extensional stress fields facilitate magma rise and thus encourage eruptions (e.g., Gudmundsson, 1990, 2006), or that fluctuating compression and extension during the passing of seismic waves trigger eruptions (Walter and Amelung, 2007; Watt et al., 2009). Stress-sensitive volcanic processes are generally not well understood and we urgently need new observational techniques and improved analytical tools to improve that understanding. All these considerations inspired the Research Topic on "Stress field control of eruption dynamics," which aimed for a thorough discussion about the state of the art, new ideas, perspectives, and challenges of the interplay between stress fields and volcanic activity.

The papers comprising the Research Topic cover a broad range of stress mechanisms affecting volcanic activity. Two reviews introduce the influence of stress change on eruption initiation and dynamics (Sulpizio and Massaro) and stress control on monogenetic volcanism (Martì et al.). The large-scale influence of tectonic stress on volcanism is discussed in two other papers (Wadge et al. Paguican and Bursik), which focus on the East African Rift and the Hat Creek Graben region, USA, respectively. The role of local stress in distinct volcanic scenarios is presented in three papers: syneruptive dynamics during caldera forming events (Costa and Martì), the opening of new vents at a mature stratovolcano like Etna (Acocella et al.), and the distribution of eruptive fissures due to 
magma chamber pressure variations (Geshi and Oikawa). The final article presents a methodology, with a few examples of application, for determining stress field in active volcanoes using focal mechanisms of earthquakes (Massa et al.).

The papers supply an up-to-date view of some important factors controlling the interplay between stress field and volcanic activity, although they represent only a sampling of the possible interactions. It emerges that the stress field can influence the eruption initiation and its dynamics, provided that the volcanic system is sufficiently close to an eruptive threshold. This is because the energy needed to trigger an eruption is usually too large for most induced stress changes to achieve (Sulpizio and Massaro). In the vicinity of large magma chambers the local stress field deviates substantially from the tectonic stress field, and controls the orientation of eruptive fissures (Geshi and Oikawa) and in the opening of new vents (Acocella et al.) even at mature central volcanoes. In the absence of large magma chambers the control of tectonic stress and its local variations play a major role in the location and frequency of volcanic activity, as in the case of monogenetic volcanism (Martì et al.) or in rift systems (Wadge et al.). The interplay between tectonic stress and volcanic activity is also a geomorphologic agent able to shape the landscape, with cascade effects on basin evolution (Paguican and Bursik). For large-scale eruptions, the control of stress field on magma pathways can control the eruptive behavior of caldera forming

\section{REFERENCES}

Gudmundsson, A. (1990). Emplacement of dikes, sills and crustal magma chambers at divergent plate boundaries. Tectonophysics 176, 257-275. doi: 10.1016/0040-1951(90)90073-H

Gudmundsson, A. (2006). How local stresses control magma-chamber ruptures, dyke injections, and eruptions in composite volcanoes. Earth Sci. Rev. 79, 1-31. doi: 10.1016/j.earscirev.2006.06.006

Rikitake, T., and Sato, R. (1989). Up-squeezing of magma under tectonic stress. J. Phys. Earth 37, 303-311.

Walter, T. R., and Amelung, F. (2007). Volcanic eruptions following M_9 megathrust earthquakes: implications for the SumatraAndaman volcanoes. Geology 35, 539-542. doi: 10.1130/G234 29A.1 events, and their intensities (Costa and Marti). Beyond these inferred lines of evidence, the quantification of stress field at volcanic systems remains elusive and difficult to assess. The method based on focal mechanisms of earthquakes (Massa et al.) is valuable in this regard, together with local studies of seismic anisotropy.

Beyond the results described in this Research Topic, a more quantitative understanding of stress field control on the different interacting parts of a volcanic system, acting on different time scales, is crucial for volcanic risk mitigation and represents one of the biggest challenges of the volcanological community. Among many, we believe that the main research lines to be pursued and developed in the near future are those dealing with (i) timing of response of magma reservoirs to external perturbations, (ii) definition of a critical state of a magma batch in relation to an external perturbation, (iii) feedback effects of stress induced by emplacement of magma at shallow crustal levels and growth of magma chambers, (iv) responses of deep magma reservoirs to strong earthquakes and their effects on shallow magma chambers.

\section{AUTHOR CONTRIBUTIONS}

All authors listed have made a substantial, direct and intellectual contribution to the work, and approved it for publication.

Watt, S. F. L., Pyle, D. M., and Mather, T. A. (2009). The influence of great earthquakes on volcanic eruption rate along the Chilean subduction zone. Earth Planet. Sci. Lett. 277, 399-407. doi: 10.1016/j.epsl.2008.11.005

Conflict of Interest Statement: The authors declare that the research was conducted in the absence of any commercial or financial relationships that could be construed as a potential conflict of interest.

Copyright (C) 2017 Sulpizio, Costa and Wadge. This is an open-access article distributed under the terms of the Creative Commons Attribution License (CC BY). The use, distribution or reproduction in other forums is permitted, provided the original author(s) or licensor are credited and that the original publication in this journal is cited, in accordance with accepted academic practice. No use, distribution or reproduction is permitted which does not comply with these terms. 